\title{
Accidental vertebral vein catheterization
}

\author{
Bruno François $\cdot$ Sami Ben-Miled
}

Received: 8 January 2014/ Accepted: 20 January 2014/Published online: 7 February 2014

(C) SIMI 2014
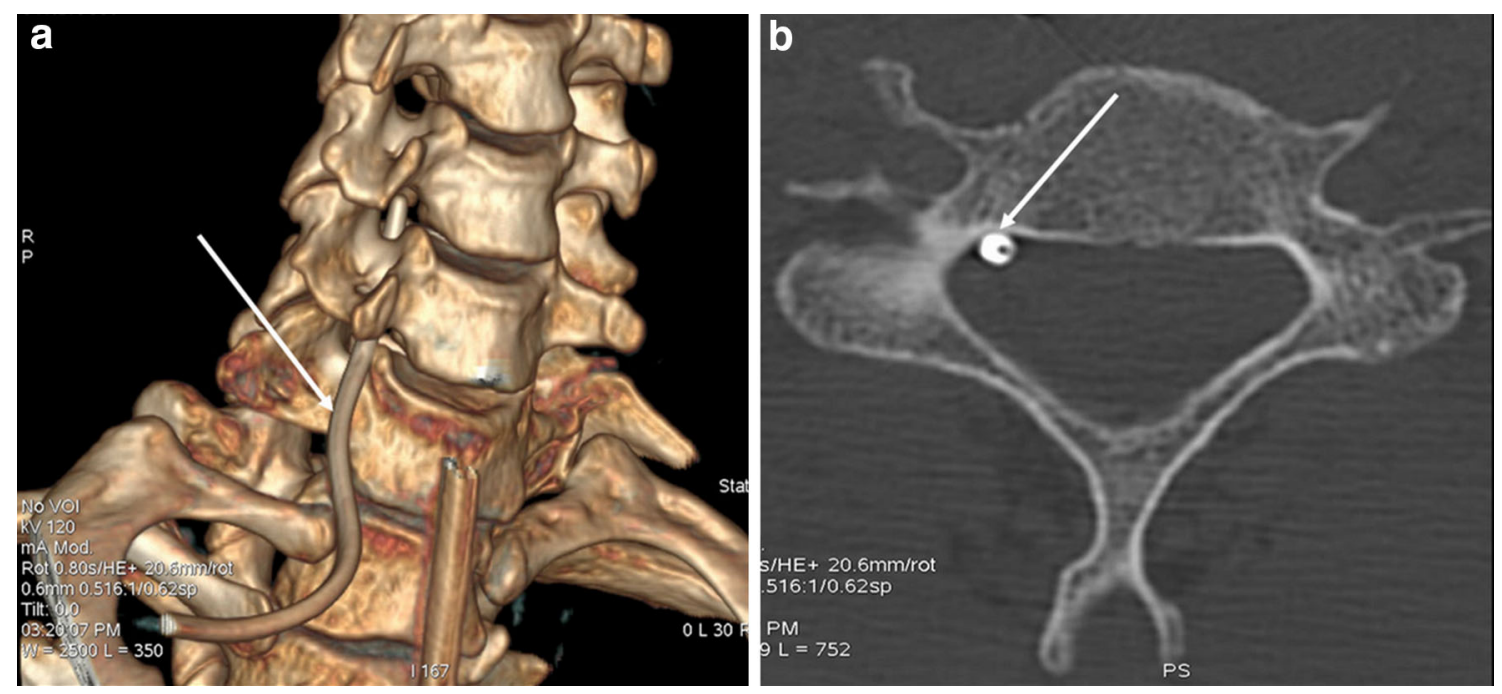

Fig. 1 a Frontal plane. White arrow shows the catheter progressing in the vertebral canal. b Transverse plane. White arrow shows catheter in the vertebral canal

A man was hospitalized for a severe traumatic brain injury secondary to a vehicle crash. The patient was intubated and mechanically ventilated on scene. At admission, a threelumen central venous catheter was inserted in the right subclavian vein using the Seldinger technique, without any difficulty. A normal backward blood flow was observed during aspiration in all three lumens, confirming the

B. François · S. Ben-Miled

Intensive Care Unit, University Hospital Dupuytren, Limoges, France

B. François $(\square)$

Réanimation Polyvalente, CHU Dupuytren, 2 Av. Martin Luther King, 87042 Limoges Cedex, France

e-mail: realim@unilim.fr appropriate catheter position within the vein, and then flushed. A chest X-ray study revealed a misplacement of the catheter with an abnormal path to the neck. A CT scan disclosed a severe head injury, and confirmed the abnormal location of the catheter within the vertebral canal (white arrows, Figure 1), due to an accidental catheterization of the right vertebral vein. This ectopic venous catheterization has not here-to-fore been described because the anatomical angulation between the right vertebral and subclavian veins usually precludes such ectopic progression of the guidewire.

\section{Conflict of interest None.}

